\title{
Synergistic Optimization of Electronic and Thermal Transport Properties for Achieving High ZT in Ni and Te Co-Substituted $\mathrm{CoSb}_{3}$
}

\author{
Ruchi Bhardwaj ${ }^{1,2}$, Parul R. Raghuvanshi ${ }^{3}$, Sanjay R. Dhakate ${ }^{1}$, Sivaiah Bathula ${ }^{1,2,4}$, Amrita \\ Bhattacharya $^{3,}$, and Bhasker Gahtori ${ }^{1,2, *}$ \\ ${ }^{1}$ CSIR-National Physical Laboratory, Dr. K.S. Krishnan Marg, New Delhi 110012, India \\ ${ }^{2}$ Academy of Scientific \& Innovative Research (AcSIR), Ghaziabad, 201002, India \\ ${ }^{3}$ Department of Metallurgical Engineering and Materials Science, IIT Bombay, Mumbai-400076, India \\ ${ }^{4}$ School of Minerals, Metallurgical and Materials Engineering, IIT Bhubaneswar, 752050, India \\ *Corresponding author: bhasker@nplindia.org; b amrita@,iitb.ac.in \\ Tel.: +91-11-45608556; Fax: +91-11-45609310
}

\section{S1. Structural parameters for theoretical calculations}

$\mathrm{CoSb}_{3}$ exhibits a cubic crystal structure with space group 204; with one Ni atom at the Co site (i.e., $\mathrm{Ni}_{0.125} \mathrm{Co}_{0.875} \mathrm{Sb}_{3}$ ), the space group becomes 148 (i.e., Rhombohedral structure). Further addition of $\mathrm{Te}$ at $\mathrm{Sb}$ site (i.e., $\mathrm{Ni}_{0.125} \mathrm{Co}_{0.875} \mathrm{Sb}_{2.958} \mathrm{Te}_{0.042}$ ), triclinic structure is formed with space group $\mathrm{P}_{1}$. On the other hand, the lattice parameter increases with the addition of $\mathrm{Ni}$ atom and further with Te atom, as given in Table S1.

Table S1: Space group and lattice parameter for the pristine and doped structures.

\begin{tabular}{ccc}
\hline Composition & Space group & Lattice parameter $(\AA)$ \\
\hline $\mathbf{C o S b}$ & & \\
& $204(\operatorname{Im} \overline{3})$ & $\mathrm{a}=\mathrm{b}=\mathrm{c} \sim 9.110$ \\
\hline $\mathbf{N i}_{\mathbf{0 . 1 2 5}} \mathbf{C o}_{\mathbf{0 . 8 7 5}} \mathbf{S b}_{\mathbf{3}}$ & $148(\mathrm{R}-3)$ & $\mathrm{a}=\mathrm{b}=\mathrm{c} \sim 9.140$ \\
\hline $\mathbf{N i}_{\mathbf{0 . 1 2 5}} \mathbf{C o}_{\mathbf{0 . 8 7 5}} \mathbf{S b}_{\mathbf{2 . 9 5 8}} \mathbf{T e}_{\mathbf{0 . 0 4 2}}$ & $1(\mathrm{P} 1)$ & $\mathrm{a} \sim 9.140, \mathrm{~b} \sim 9.145, \mathrm{c}$ \\
& & $\sim 9.146$ \\
\hline
\end{tabular}

\section{S2. Density}

The relative density of all the synthesized samples has been calculated utilizing the experimental density observed employing the Archimedes principle and standard density of pristine $\mathrm{CoSb}_{3}$. Table $\mathrm{S} 2$ shows the experimental and relative density of all the synthesized $\mathrm{Ni}_{0.07} \mathrm{Co}_{0.93} \mathrm{Sb}_{3-\mathrm{x}} \mathrm{Te}_{\mathrm{x}}(\mathrm{x}=0.02,0.04,0.06,0.08)$ samples. 
Table S2: Experimental and relative density of all the synthesized samples.

\begin{tabular}{ccc}
\hline Sample & Density & Relative density \\
\hline $\mathbf{N i}_{\mathbf{0 . 0 7}} \mathbf{C o}_{\mathbf{0 . 9 3}} \mathbf{S b}_{\mathbf{2 . 9 8}} \mathbf{T e}_{\mathbf{0 . 0 2}}$ & 7 & $\sim 92 \%$ \\
\hline $\mathbf{N i}_{\mathbf{0 . 0 7}} \mathbf{C o}_{\mathbf{0 . 9 3}} \mathbf{S b}_{\mathbf{2 . 9 6}} \mathbf{T e}_{\mathbf{0 . 0 4}}$ & 7.15 & $\sim 94 \%$ \\
\hline $\mathbf{N i}_{\mathbf{0 . 0 7}} \mathbf{C o}_{\mathbf{0 . 9 3}} \mathbf{S b}_{\mathbf{2 . 9 4}} \mathbf{T e}_{\mathbf{0 . 0 6}}$ & 7.23 & $\sim 95 \%$ \\
\hline $\mathbf{N i}_{\mathbf{0 . 0 7}} \mathbf{C o}_{\mathbf{0 . 9 3}} \mathbf{S b}_{\mathbf{2 . 9 2}} \mathbf{T e}_{\mathbf{0 . 0 8}}$ & & \\
\hline
\end{tabular}

\section{S3. Specific Heat}

The temperature-dependent specific heat $(\mathrm{Cp})$ measured utilizing the differential scanning calorimetry (DSC) instrument is shown in Fig. S1.

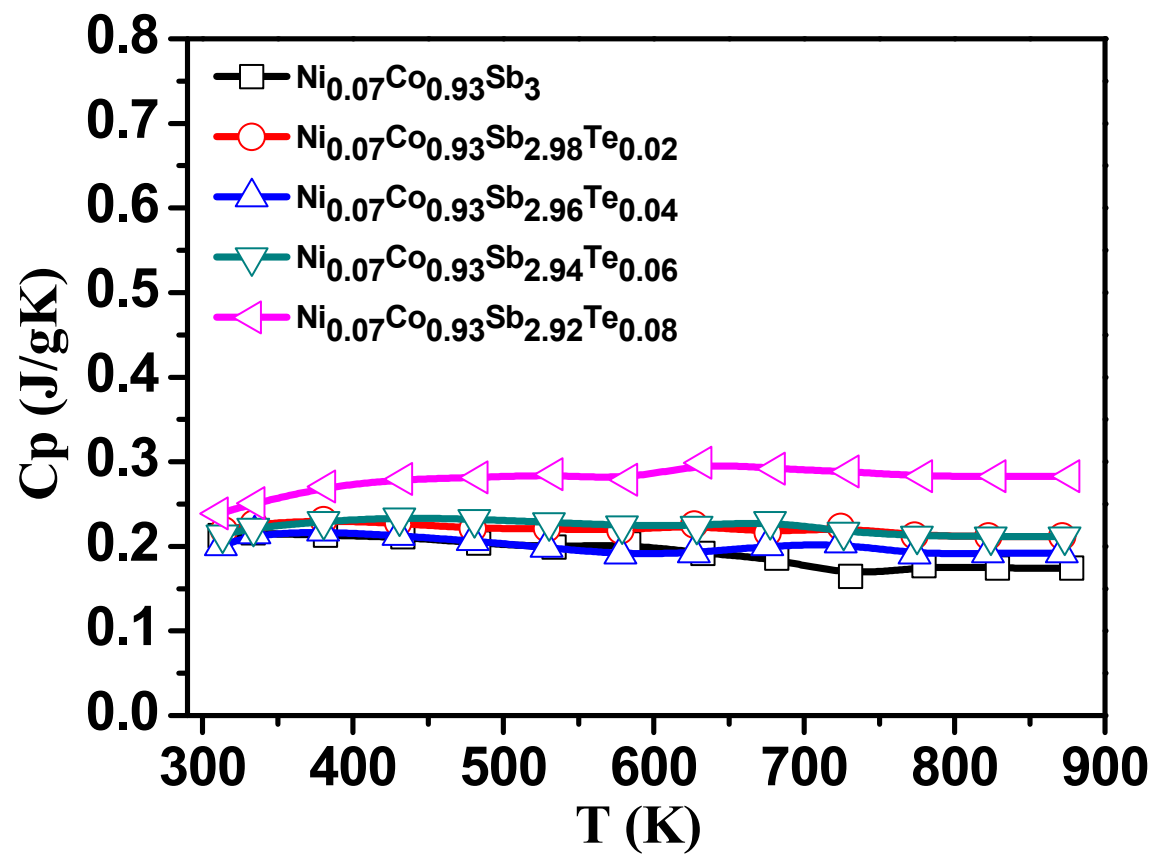

Figure S1: Temperature dependence of specific heat of the synthesized $\mathrm{Ni}$ and $\mathrm{Te}$ co-doped $\mathrm{CoSb}_{3}$ samples. 